\title{
Modelling of carbon monoxide dispersion along roads with the use of the finite element method
}

\author{
W. Kamiński, M. Kucharski, E. Tomczak \& J. Petera \\ Faculty of Process and Environmental Engineering, \\ Technical University of Lodz, Poland
}

\begin{abstract}
CFD models are used in air protection to simulate the spreading of gaseous pollutants. The CFD models allow us to obtain the necessary information on the liquid flow (velocity and pressure distribution fields), heat and mass transfer. This is achieved by numerically solving the differential equations which describe momentum transfer as well as energy and mass balances.

The proposed model was based on a three-dimensional calculation grid, which represented a fragment of the environment around a considered road segment. The calculation grid was built from regular rectangular eight-node elements and mapped a two-lane road.

In the grid model, cubicoids representing automobiles and trucks were placed in an air flow. The size and number of the cubicoids corresponded to the mean size of automobiles, trucks, the traffic intensity and mean velocity. For such a system, equations of air flow turbulence were solved. Next, taking into account the estimated pollutant emission and solving mass transport equation, carbon monoxide concentration profiles were calculated. The system of partial differential equations was solved using the finite element method. The software proposed by the authors was used. To verify the method, measurements were made at a selected street in Lodz, measuring the level of $\mathrm{CO}$, recording wind velocity and direction, temperature, pressure and air humidity as well as the degree of clouding and additionally recording the number and the vehicle motion. Based on the film, one can determine the intensity of vehicle motion classified into trucks and automobiles and average traffic velocity. The data was used not only to obtain model parameters, but also allowed us to assess accuracy of the prediction.
\end{abstract}

Keywords: traffic emission, pollution modelling, $C O$ dispersion, finite element method. 


\section{Introduction}

The contribution of road transport to global air pollution is very high, and in industrialised countries it is equal or even exceeds the pollution generated by industry. On a global scale, cars release nearly 300 million tonnes of toxic exhaust emissions annually. It is estimated that big urban agglomerations in Europe are inhabited by $70-80 \%$ of its population. Due to the size and character of vehicle exhaust emission, local conditions which hamper quick ventilation of streets and a continually growing number of vehicles, the percentage of people exposed to the harmful effect of toxic components of vehicle exhausts is still very high.

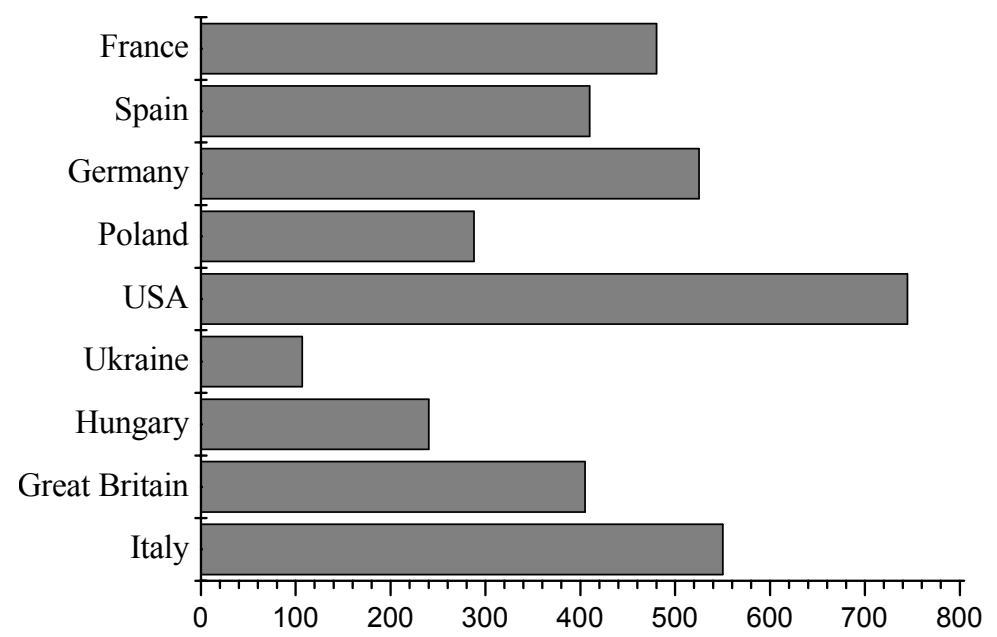

Figure 1: Number of cars per 1000 people in selected countries in 2000 (Statistical Yearbook, 2003).

According to the latest literature, street traffic can be treated as the main source of air pollution in big cities. In certain regions its contribution to the emission of carbon monoxide $\mathrm{CO}$ is estimated to be ca. $70 \%$ or even $90 \%$, and the emission of nitric oxides $\mathrm{NO}_{\mathrm{x}}$ amounts to $23 \%$, while according to other authors this is $98 \%$ and $20 \%$, respectively [1,2]. Carbon monoxide is also referred to as the biggest source of organic carbon emitted in the form of aerosols. According to researches carried out in Athens, street traffic is responsible for $8 \%$ of the pollution with sulphur dioxide $\mathrm{SO}_{2}$, in $67 \%$ with nitric oxides $\mathrm{NO}_{\mathrm{x}}$, in $64 \%$ with hydrocarbons $\mathrm{C}_{\mathrm{x}} \mathrm{H}_{\mathrm{y}}$ and in almost $100 \%$ with carbon monoxide $\mathrm{CO}$ [3].

Tools to estimate the effect of street traffic on air quality in urban agglomerations are based on various types of mathematical models. When assumed conditions are considered, it is possible to determine the behaviour of pollutants in a street canyon, open road, cross roads or even on a pavement. 
Possible impacts of initial conditions, such as exhaust emissions and building layout, allow us to determine concentration fields of toxic substances in the air. Models that describe pollutant dispersion and transport in the air can be classified according to various criteria. One of them is space scale in which global, regional and local models can be distinguished. The next classification is made in reference to time, i.e. the time of averaging pollutant concentrations. American regulations give the period of $1,3,8$ and 24 hours as the main reference times in short-term models, while in long-term models the averaging times range from 1 month to 1 year. The models of dispersion can also be divided into these which are used to calculate changes in the concentrations of toxic compounds during a set period of time in selected receptors and the models which calculate spatial concentration fields in a given time instant. An additional classification criterion is the degree of urbanisation. Here, we have urban and rural areas which differ in a roughness coefficient and meteorological exponent for subsequent classes of atmosphere equilibrium. Due to their complexity, the models can be divided into refined and screening ones. In the refined models numerous factors are taken into account, which enable much more precise calculation of concentrations. However, they require a large number of data which are not always easily available. The screening models are usually applied to roughly estimate pollution or to simulate changes in the trends of toxic compound concentrations [4]. Taking into account the mathematical approach, the models of pollutant dispersion can be divided into several main groups: box models, Gaussian models, receptor, Euler and stochastic models. The classification of models according to the above criteria is given by Vardoulakis et al. [5].

\section{Description of the method}

To simulate a phenomenon, process or object, its mathematical model should be known. It is usually composed of algebraic, ordinary differential, partial or integral equations. So, the simulation consists in solving a system of equations. In the case of vehicle traffic and gas pollutant dispersion, there is a turbulent fluid motion. Basic equations which describe such a flow are the Navier-Stokes equations. For an incompressible fluid the momentum conservation equation should be completed with a continuity equation.

$$
\begin{gathered}
\nabla \cdot \mathrm{u}=0 \\
\nabla \cdot\left(\left(\mu+\mu_{\mathrm{t}}\right)\left(\nabla \mathrm{u}+(\nabla \mathrm{u})^{\mathrm{T}}\right)\right)-\nabla \mathrm{p}-\rho \mathrm{g}=0
\end{gathered}
$$

The turbulent viscosity coefficient in the Navier-Stokes equation is calculated from the Prandtl-Kolmogorov relation which refers to kinetic energy of dissipation $\mathrm{K}$ and the length of mixing path $1_{\mu}$. 


$$
\begin{gathered}
\nabla \cdot\left(\left(\mu+\frac{\mu_{t}}{\sigma_{K}}\right) \nabla K\right)+\mu_{t} \gamma^{2}-\rho C_{D} \frac{K^{3 / .2}}{1_{\mu}}=0 \\
\mu_{t}=\rho C_{\mu} K^{1 / 2} 1_{\mu}
\end{gathered}
$$

where

$$
1_{\mu}=\kappa \delta
$$

$\delta \quad$ - distance from the nearest wall, $\gamma$ - local shearing rate, $\kappa$ - von Karman constant, $\sigma_{K}$ - turbulent Prandtl number, $C_{D}, C_{\mu}$ - empirical coefficients.

The system of equations was completed with a pollutant transport equation, in which the release rate of a pollutant, i.e. carbon monoxide emission source, was considered.

$$
\begin{aligned}
\frac{\mathrm{Dc}}{\mathrm{Dt}} & =\nabla \cdot\left(\left(\mathrm{D}+\mathrm{D}_{\mathrm{t}}\right) \nabla \mathrm{c}\right)+\mathrm{Q} \\
\mathrm{c} & =\mathrm{f}(\mathrm{x}(\mathrm{t}), \mathrm{y}(\mathrm{t}), \mathrm{z}(\mathrm{t}), \mathrm{t})
\end{aligned}
$$

The turbulent diffusion coefficient was determined from the equation:

$$
D_{t}=\frac{\mu_{t}}{S c}
$$

where:

$\mu_{\mathrm{t}} \quad$ turbulent viscosity

Sc Schmidt number

The proposed system of equations with boundary conditions was solved using the finite element method [6]. A road segment $80 \mathrm{~m}$ long is analysed in the model. The analysed segment is a two-lane road $7.5 \mathrm{~m}$ wide with $20 \mathrm{~m}$ shoulder on each side. The analysed height above the road level was $15 \mathrm{~m}$. Vehicles in the calculations were represented by cubicoids of dimensions equal to average dimensions of passenger vehicles and lorries. It was also assumed that pollutant dispersion was an isothermal process. The emission and dispersion of carbon monoxide were considered in the calculations. Carbon monoxide emission was estimated according to Copert 3 algorithm [7]. Statistical data concerning the number of cars, engine size and $\mathrm{CO}$ emission, with reference to various aspects of operation of combustion and diesel engines, was included in the calculations.

Calculations were started with the determination of a velocity profile. It was assumed that the $\mathrm{CO}$ concentration profile was a result of two overlapping 
effects: motor traffic and turbulence caused by the traffic as well as air flow resulting from meteorological conditions (wind direction and velocity). These effects were included in two subsequent procedures of velocity field calculation. At the first stage, cars were motionless while the environment was moving at a velocity resulting from mean vehicle velocity. An initial condition at this stage of calculations was a constant initial velocity of the moving environment. As a result of an iteration, a profile of air flow along the road was formed. The profile was recorded by a computer. Next, a velocity profile resulting from air flow was calculated. It was calculated irrespective of the previous profile. At this stage the air flow was also assumed to be constant. Using iteration, a proper velocity profile was obtained both in the vicinity and on the road.

In the proposed model of pollutant dispersion, the calculations were divided into two stages. The principle of superposition was also used. The first stage covers exhaust emission and dispersion resulting from motor traffic (velocity profiles from the first stage of the simulation). At the second stage there is a further dispersion due to air flow resulting from atmospheric conditions. During simulation, the above discussed stages followed each other until reaching a steady state. For exhaust emissions, the initial concentration on the road was zero. Next, as a result of exhaust emission and dispersion a concentration distribution was obtained. The concentration profile was also modified in subsequent iterations until reaching the steady state.

\section{Measuring methods}

Measurements were taken near a two-lane road with heavy traffic. The measuring set-up was situated on a straight road segment within Lodz boundaries. On the whole, a series of ca. 177 measurements were taken in the spring and autumn season. The measured substance was carbon monoxide because of its amount formed during liquid fuel combustion and especially harmful impact on the health of people in general and car drivers in particular.

The concentration of carbon monoxide was measured by a CO12M analyser (Environment S.A.) used for analyses in continuous or batch systems. The device is especially useful at low pollutant concentrations in the ambient air in atmospheric conditions and is characterised by a detection limit of $0.05 \mathrm{ppm}$. Its operation is based on detecting the rate of absorption of infrared radiation. To measure temperature, humidity and wind velocity, an ALMEMO 2290-3 device (Ahlborn, Germany) was applied. Additionally, the traffic was filmed by a JVC camera. Based on the records, the number, types and average driving speed of the vehicles were determined. The recorded data is given in Table 1.

\section{Results and discussion}

Simulation, made by means of the model described above, consisted of solving the proposed system of equations in all nodes of the assumed calculation domain and determination of the concentration fields of the considered pollutant in time 
and space. Results obtained in this way allowed us to obtain concentrations in arbitrary cross sections of the calculation grid. The calculations were made for all input data taken from real measurements and they were compared with the measured carbon monoxide concentrations. Figures 2 and 3 show the effect of wind velocity and traffic intensity on the concentration profile, respectively.

Based on the data obtained, the $\mathrm{CO}$ concentration on the road edge was recorded in the locations in which the measurements were actually taken. A comparison of experimental and calculated data is given in Table 2.

The correlation coefficient was compared with the values of $\mathrm{R}$ found in literature for other grid models (Table 3).

Table 1: $\quad$ Measurements taken on the road - the type and range of values.

\begin{tabular}{|c|l|c|c|}
\hline \multicolumn{1}{|c|}{ Measured value } & \multicolumn{2}{c|}{ Range } \\
\hline 1 & Traffic density of passenger cars & car/s & $0.37-0.70$ \\
\hline 2 & Traffic density of lorries & lorry/s & $0.008-.038$ \\
\hline 3 & $\begin{array}{l}\text { Level on which CO concentration was } \\
\text { measured }\end{array}$ & $\mathrm{m}$ & $0-1.5$ \\
\hline 4 & Wind direction & $\mathrm{o}$ & $0-360$ \\
\hline 5 & Wind power & $\mathrm{m} / \mathrm{s}$ & $0-3.4$ \\
\hline 6 & Air temperature & ${ }^{\circ} \mathrm{C}$ & $2-27.9$ \\
\hline 7 & Moisture content & $\%$ & $33.2-94.4$ \\
\hline 8 & Total cloud amount & - & $1 / 8-8 / 8$ \\
\hline
\end{tabular}

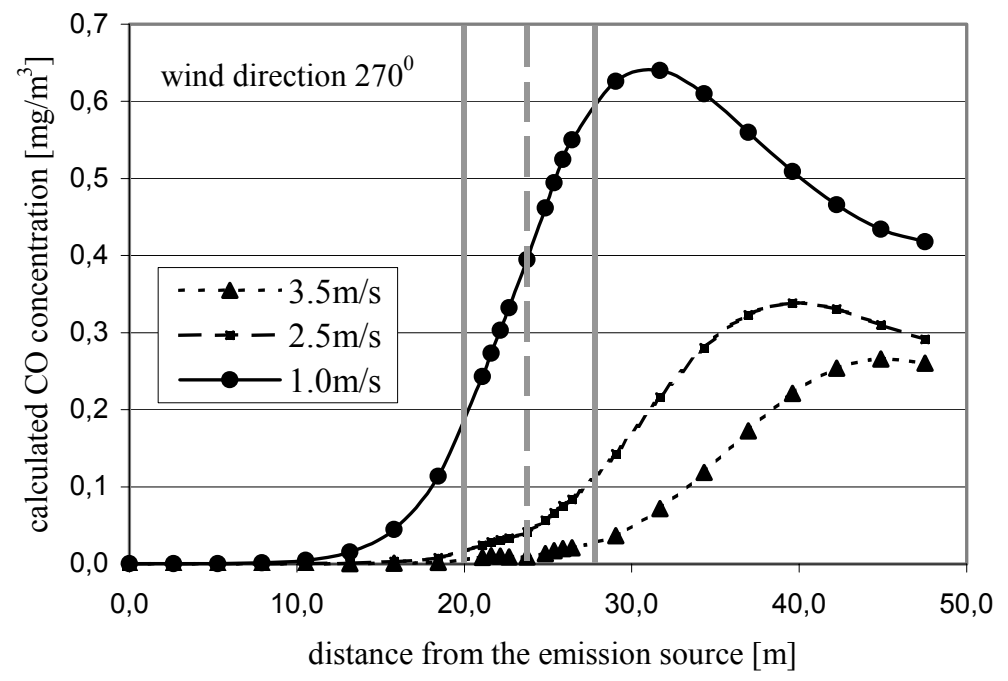

Figure 2: A comparison of concentration profiles for different wind velocities. 


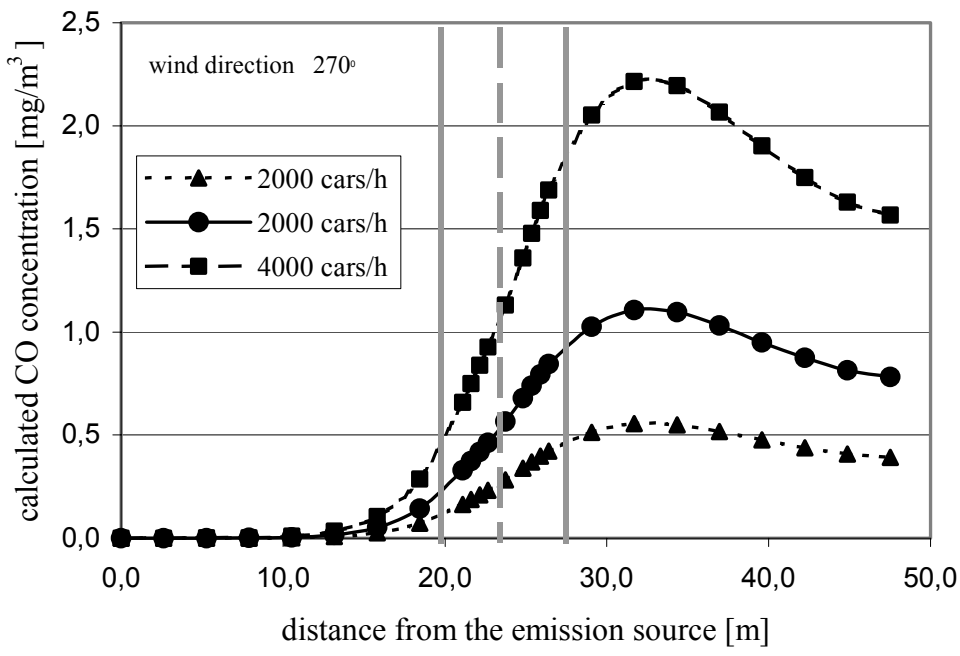

Figure 3: A comparison of concentration profiles for different traffic intensities on the road.

Table 2: $\quad$ Statistical evaluation of the grid model.

\begin{tabular}{|c|c|c|c|c|}
\hline & \multicolumn{4}{|c|}{ Wind direction } \\
\cline { 2 - 5 } & $180^{\circ}$ & $220^{\circ}-230^{\circ}$ & $270^{\circ}$ & $220^{\circ}-230^{\circ}$ \\
\hline $\begin{array}{c}\text { Correlation } \\
\text { coefficient, } \mathrm{R}\end{array}$ & 0.80 & 0.83 & 0.77 & 0.83 \\
\hline $\begin{array}{c}\text { Root mean } \\
\text { square error, } \delta\end{array}$ & 0.31 & 0.39 & 0.30 & 0.40 \\
\hline
\end{tabular}

Table 3: $\quad$ Comparison of the proposed model and other grid models.

\begin{tabular}{|c|c|c|}
\hline Model & $\mathrm{R}$ & Literature source \\
\hline Our model & 0.81 & - \\
\hline Miskam & 0.69 & Lohmeyer et al., 2002 [8] \\
\hline OSPM & 0.80 & Berkowicz et al., 2002 [9] \\
\hline
\end{tabular}

\section{Conclusions}

1. The grid model used in the recording of specific situations on the road, despite the application of relevant equations which describe fluid flow and exhaust dispersion, requires far reaching simplifications resulting from complexity of the studied issue. 
2. The main advantage of the proposed model is that carbon monoxide concentration can be determined in an arbitrary point of the considered calculation domain.

3. Accuracy of the calculated values is a result of the assumed simplifications and estimated $\mathrm{CO}$ emission.

\section{References}

[1] Qin Y., Chan L.Y., Traffic source emission and street level air pollution in urban areas of Guangzhou, Atmospheric Environment 27B, pp. 275-282, 1993.

[2] Luria M., Weisinger R., Peleg M., CO and NOx levels at the center of city roads in Jerusalem, Atmospheric Environment, 24B, pp. 93-99, 1988.

[3] Mukherjee P., Viswanathan S., Carbon monoxide modelling from transportation sources, Chemosphere, 45, pp. 1071-1083, 2001.

[4] Neumann M., Mathematical models of short range pollutant dispersion in US-EPA methodology, Conference Proceedings Pol-Imis, Poland, pp. 162-175, 1997.

[5] Vardoulakis S., Fisher E.A.B., Pericleous K., Modelling air quality in street canyons: a review, Atmospheric Environment, 37, pp. 155-182, 2003.

[6] Kaminski K., Kaminski W., Petera J.; A three-dimensional numerical model of air pollutant dispersion; Air Pollution XIII; Ed. C.A. Brebbia, WIT Press 2005, p.39-48

[7] Buron J.M., Lopez J.M., Aparicio F., Estimation of road transportation emissions in Spain from 1988 to 1999 using COPERT III program, Atmospheric Environment, 38, pp. 715-724, 2004.

[8] Lohmeyer A., Eichhorn J., Flassak T., WinMISKAM 4.2 - microscale flow and dispersion model for built up areas, recent developments, 11th International Symposium Transport and Air Pollution, 2, 2002.

[9] Berkowicz R., Ketzel M., Vachon G., Louka P., Rosant J.M., Mestayer P.G., Sini J.-F., Examination of traffic pollution distribution in a street canyon using the Nantes'99 experimental data and comparison with model results, Water, Air and Soil Pollution Focus, 2, (14), 5-6, pp. 311324, 2002. 